\title{
SPECTRA OF LAPLACIANS ON FORMS ON AN INFINITE GRAPH
}

\author{
HÈLA AYADI
}

Abstract. In the context of infinite weighted graphs, we consider the discrete Laplacians on 0 forms and 1 -forms. Using Weyl's criterion, we prove the relation between the nonzero spectrum of $\Delta_{0}$ and that of $\Delta_{1}$. Moreover, we give an extension of the work of John Lott to characterize the 0 -spectrum of these two Laplacians.

Mathematics subject classification (2010): 39A12, 05C63, 05C05, 47A53.

Keywords and phrases: Infinite weighted graph, discrete Laplacian, Weyl's criterion, spectrum.

\section{REFERENCES}

[1] C. Anné, N. Torki-Hamza, The Gauss-Bonnet Operator of an Infinite Graph, Analysis Mathematical Physics 5 (2015) 137-159.

[2] H. AYADI, Semi-Fredholmness of the discrete Gauss-Bonnet operator, to appear in Filomat (2015).

[3] H. Baloudi, S. Golénia, A. Jeribi, The Adjacency Matrix and the Discrete Laplacian Acting on Forms, preprint arXiv:1505.06109(2015).

[4] Y. Colin DE Verdière, Spectre de Graphes, Cours spécialisés, volume 4 Société Mathématique de France (1998).

[5] J. DodZIUK, Elliptic operators on infinite graphs. Analysis, geometry and topology of elliptic operators, World Sci. Publ., Hackensack NJ. (2006) 353-368.

[6] D. E. DutKay, P. E. T. JoRGensen, Spectral theory for discrete Laplacians, Complex analysis and operator theory 1 (2010) 1-38.

[7] K. FuJiwara, The Laplacian on rapidly branching trees, Duke mathematical journal 83 (1996) 191202.

[8] A. GRIGOR'YAN, Analytic and geometric background of recurrence and non-explosion of the Brownian motion on Riemannian manifolds, Bulletin of the American Mathematical Society 36 (1999) $135-249$.

[9] A. GRIGOR'YAN, Analysis on graphs, Lecture Notes (2011/2012).

[10] M. Gromov, Asymptotic Invariants of Infinite Groups, Geometric Group Theory, vol. 2, ed. by Graham Niblo and Martin Roller, London Math. Soc. Lecture Notes 182, Cambridge University Press, Cambridge (1993).

[11] J. LotT, The zero-in-the spectrum question, Enseign. Math 42 (1996) 341-376.

[12] R. Lyons, Y. Peres, Probability on Trees and Networks, Cambridge University Press, New York (2016), available at http: / /pages.iu.edu/ rdlyons/.

[13] B. Mohar, W. Woess, A survey on spectra of infinite graphs, Bull. London Math. Soc. 21, (1989) 209-234.

[14] M. ReEd, B. Simon, Methods of Modern Mathematical Physics I, Academic Press (1980).

[15] T. SHIRAI, The spectrum of infinite regular line graphs, Transactions of the American Mathematical Society 352 (2000) 115-132.

[16] P. M. SoARd, Potential Theory on Infinite Networks, Lecture Notes in Mathematics 1590 (1994).

[17] P. M. SOARDI, W. WoEss, Uniqueness of currents in infinite resistive networks, Discrete Applied Mathematics 31 (1991) 37-49.

[18] R. S. Strichartz, Transformation of spectra of graph laplacians, Rocky Mountain Journal of Math, 40 (6) (2010). 
[19] N. Torki-HamZA, Laplaciens de graphes infinis I-Graphes métriquement complets, Confluentes Mathematici 2 (2010) 333-350, translated to Laplacians of infinite graphs. I: Metrically complete graphs, Arxiv:1201.4644.

[20] W. WoESS, Random walks on infinite graphs and groups, Bulletin of the London Mathematical Society 26 (1994) 1-60. 